Lesser Sunda

P-ISSN: 2775-0078

Januari 2021

E-ISSN: 2775-0086

Vol. 1(5):29-35

\title{
Pola Pertumbuhan Ikan Pari Kemejan (Rhynchobatus springeri) yang Didaratkan di Kubu Raya, Kalimantan Barat
}

\author{
Fitra Wira Hadinata ${ }^{1 *}$, Sri Rahayu ${ }^{1}$, Fitri Nurleha ${ }^{1}$, Kezia Gloria A.R. ${ }^{2}$, Benaya M.S. ${ }^{3}$ \\ ${ }^{1}$ Manajemen Sumberdaya Perairan, Universitas Tanjungpura \\ ${ }^{2}$ Konservasi Kelautan, Akademi Komunitas Kelautan dan Perikanan Wakatobi \\ ${ }^{3}$ Wildlife Conservation Society-Indonesia Porgram \\ fitra.wirahadinata@faperta.untan.ac.id
}

Naskah diterima : 8 Desember 2020, Disetujui : 16 Januari 2021

\begin{abstract}
The whitespotted guitarfish (Rhyncobatus Springeri) resource is an important commodity and has high economic value. This study aims to determine the growth pattern of whitespotted guitarfish landed in the PPI Sungai Kakap. This research was conducted at the PPI Sungai Kakap, Sungai Kakap District, Kubu Raya Regency, West Kalimantan Province in July and August 2019. Data was collected by observation, surveys, and interviews. Data analysis of sex ratios, length, and weight was carried out on samples of whitespotted guitarfish. The results of the analysis of the sex ratio of male and female whitespotted guitarfish were 1.00:1.44, this shows that the number of male fish caught is relatively equal to the number of female fish caught. The results of the analysis of the length and weight relationship of whitespotted guitarfish, the a value is 20.643 and the $b$ value is 0.6770 . That value represents a negative allometric growth pattern for male and female fish. The negative allometrics explain that the length growth is faster than the weight growth. Generally, the increase of the length and weight is equal, but the whitespotted guitarfish has length growth faster than weight growth.
\end{abstract}

Keywords : Growth patterns, sex ratio, growth patterns

\section{PENDAHULUAN}

Ikan pari kemejan termasuk ke dalam genus Rhynchobatus dari famili Rhinidae. Ikan ini merupakan target tangkapan utama nelayan gillnet di Kubu Raya. Seluruh bagian tubuh ikan pari kemejan dapat dimanfaatkan dan bernilai ekonomis. Kulitnya dapat dijadikan bahan baku dan diolah menjadi suatu kerajinan yang bernilai ekonomis tinggi, salah satunya seperti pembuatan tas bagi sebagian masyarakat, Jayadi (2011). Daging ikan hiu dan pari untuk bahan pangan(bakso, sosis, ikan kering); sirip untuk sop; kulit untuk bahan kerajinan kulit (tas, sepatu, jaket,dompet); minyak, gigi dan tulang dapat digunakan untuk bahan obat dan lem (Musick et al., 2000). Balai Pengelolaan Sumberdaya Pesisr dan Laut (BPSPL) Pontianak mencatat bahwa jumlah pari yang didaratkan di Pangkalan Pendaratan Ikan (PPI) Sungai Kakap sepanjang tahun 2018 adalah sebanyak 36.707 ekor. Spesies dari ikan pari tersebut yang paling banyak tertangkap adalah pari kemejan. 
Pari kemejan saat ini menjadi isu hangat di lingkungan penggiat konservasi karena penangkapan terhadap pari jenis ini cukup tinggi akibat permintaan siripnya yang tinggi. Jumlah sirip Rhynchobatus australiae yang didaratkan di PPI Sungai Kakap adalah $7.710,5 \mathrm{~kg}$, dengan perkiraan nilai $\mathrm{Rp}$. 7.324.9725.000. Selain itu, jumlah sirip dari jenis Rhynchobatus springeri adalah 6.858,1 $\mathrm{kg}$, dengan perkiraan Rp.5.486.480.000. Jika dijumlahkan sepanjang 2018, maka total sirip dari kedua jenis ini berjumlah 14.568,6 kg yang di daratkan di PPI Sungai Kakap, dengan total perkiraan nilai sirip adalah $\mathrm{Rp}$. 78.736.205.000 (BPSPL Pontianak, 2018). Adapun daerah penangkapan pari kemejan yang didaratkan di PPI Sungai Kakap yaitu sekitar Perairan Laut Cina Selatan, Laut Natuna, dan Selat Karimata (bagian dari WPP-NRI 711).

Sejauh ini data yang tersedia terkait sumberdaya ikan pari kemejan yaitu produksi dan berat. Belum terdapat data dan informasi terkait pola pertumbuhan. Informasi ini penting untuk melakukan pengelolaan sumberdaya ikan pari kemejan. Penelitian ini penting dilakukan karena eksploitasi sumber daya ikan pari kemejan yang ada di Kalimantan Barat sangat tinggi. Penelitian ini diharapkan dapat memberikan gambaran mengenai kondisi sumber daya ikan serta dapat memberikan saran pengelolaan yang dapat dijadikan sebagai bahan evaluasi dan penentuan kebijakan yang akan diterapkan terhadap eksploitasi sumberdaya ikan pari kemejan.

\section{METODE PENELITIAN}

Penelitian ini dilaksanakan di PPI Sungai Kakap, Kecamatan Sungai Kakap, Kabupaten Kubu Raya, Provinsi Kalimantan Barat. Penelitian ini dilaksanakan pada Bulan Juli dan Agustus 2019.

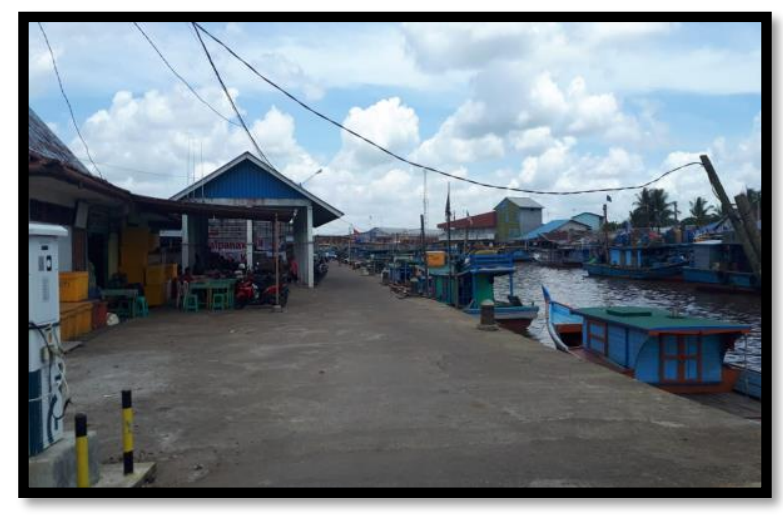

Gambar 1 Lokasi Penelitian, PPI Sungai Kakap

\section{Pengumpulan Data}

1. Wawancara

Wawancara dilakukan dengan nelayan, pemilik kapal dan petugas PPI Sungai Kakap yang berda di lapangan maupun dikantor. Wawancara dilakukan dengan untuk mengetahui keadaan sumberdaya perikanan ikan pari kemejan.

\section{Observasi}

Observasi merupakan suatu teknik dalam pengumpulan data yang dilakukan melalui pengamatan objek kemudian dilakukan pencatatan dari hasil yang diperoleh. Observasi dilakukan terhadap kondisi dan lingkungan PPI Sungai Kakap dan morfologi ikan pari kemejan.

\section{Analisis Data}

1. Nisbah kelamin

Analisis rasio ikan menggunakan rumus menurut Effendie (1997) sebagai berikut :

Rasio Kelamin $=\frac{M}{F}$ 
Dimana : $\mathrm{M}=$ jumlah ikan jantan,

$\mathrm{F}=$ jumlah ikan betina

\section{Pertumbuhan ikan}

Analisis pertumbuhan dilakukan untuk mengetahui hubungan panjang bobot ikan pari kemejan, seperti yang dikemukakan oleh Hile, 1963 dalam Effendie, 1997 :

$$
\mathrm{W}=\mathrm{a} \mathrm{L}^{\mathrm{b}}
$$

Dimana : W = bobot ikan $(\mathrm{g})$,

$\mathrm{L}=$ panjang total ikan $(\mathrm{mm})$

$\mathrm{a}$ dan $\mathrm{b}=$ konstanta

Kemudian ditransformasikan ke dalam bentuk logaritma, sehingga membentuk persamaan garis lurus sebagai berikut :

\section{$\log \mathrm{W}=\log \mathrm{a}+\mathrm{b} \log \mathrm{L}$}

Nilai b yang didapat dari persamaan di atas akan menunjukan pola pertumbuhan isometrik dan allometrik. Pola pertumbuhan isometrik jika $\mathrm{b}=3$, yang berarti pertumbuhan ikan seimbang antara pertumbuhan panjang dengan pertumbuhan bobotnya. Tetapi jika nilai $b<3$ berarti pertambahan panjangnya lebih cepat daripada pertambahan bobotnya (allometrik negatif), dan jika $b>3$ maka pertambahan bobotnya lebih cepat dari pertambahan panjangnya (allometrik positif). Untuk

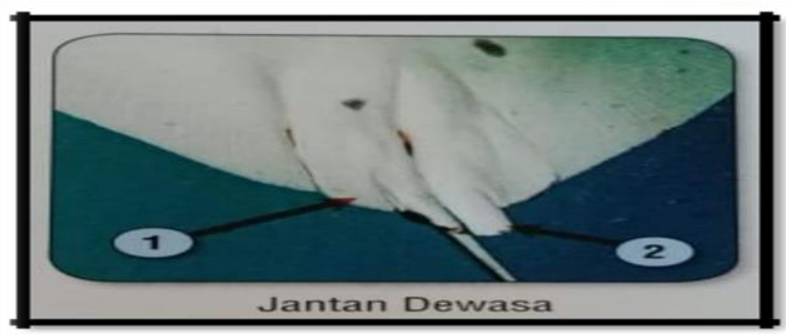

Ikan Pari Jantan mengetahui nilai $\mathrm{b}=3$ atau $\mathrm{b} \neq 3$ maka dilakukan uji-t dengan hipotesis : Ho $: b=3$, hubungan panjang dengan bobot adalah isometrik.

\section{HASIL DAN PEMBAHASAN}

Hasil dari enumerasi Kantor Pengawas Sumber Daya Kelautan dan Perikanan (PSDKP) Pontianak tahun 2018 tercatat 54 kapal gillnet dasar, 3 kapal gillnet nylon, 3 kapal bouke ami, dan 5 kapal pengangkut. Ukuran kapal-kapal yang sandar di PPI Sungai Kakap adalah < 30 Gross tonnage (GT). Daerah penangkapan kapal-kapal gillnet dasar adalah perairan Karimata dan sekitar Kepulauan Natuna. Alat tangkap yang digunakan untuk menangkap ikan pari kemejan yaitu gillnet dasar dengan mesh size 4-16 inchi dan dilengkapi sarana kapal motor yang berukuran 16-29 GT. Lama waktu trip penangkapan adalah 20-50 hari (BPSPL Pontianak, 2018).

Seksualitas ikan perlu diketahui karena dapat digunakan untuk membedakan antara ikan jantan dengan ikan betina. Ikan jantan adalah ikan yang dapat menghasilkan spermatozoa, sedangkan ikan betina adalah ikan yang dapat menghasilkan sel telur atau ovum (Effendie, 1997). jenis kelamin Pari adalah sebagai berikut :

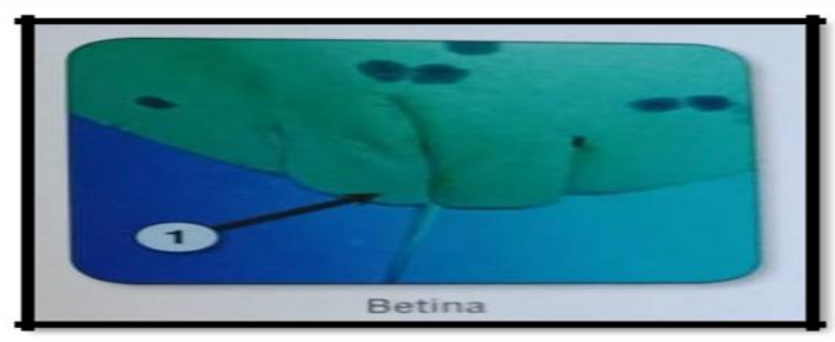

Ikan Pari Betina

Gambar 2 Jenis kelamin ikan pari (Sumber: Sadili, 2014) 
Ikan jantan dapat dibedakan dari ikan betina dengan melihat ciri-ciri seksual primer dan sekunder. Ciri seksual primer adalah organ yang secara langsung berhubungan dengan proses reproduksi. Ciri-ciri seksual sekunder adalah dengan melihat warna tubuh (sexual dichromastism), morfologi dan bentuk tubuh (sexual dimorphism) yang digunakan untuk membedakan jenis kelamin pada ikan. Testis beserta salurannya merupakan ciri seksual primer ikan jantan, sedangkan ovari beserta salurannya merupakan ciri seksual primer ikan betina (Effendie, 1997). Menurut Omar (2009), di Sungai Musi Sumatera Selatan memiliki pola pertumbuhan allometrik positif untuk ikan jantan dan ikan betina (Sari, 2007). nisbah ikan jantan dan ikan betina diperkirakan mendekati 1 : 1 , berarti jumlah ikan jantan yang tertangkap relatif sama banyaknya dengan jumlah ikan betina yang tertangkap. Menurut Harlyan (2015), resiko penurunan populasi atas tingginya kegiatan penangkapan hiu dapat ditunjukkan dari beberapa hal diantaranya adalah nisbah kelamin dan tingkat kematangan klasper. Hasil analisis nisbah kelamin ikan pari kemejan Jumlah sampel ikan pari yang diperoleh selama penelitian sebanyak 100 ekor yang terdiri dari 41 ekor ikan jantan dan 59 ekor ikan betina, dengan demikian, nisbah kelamin ikan pari jantan dan betina adalah $1,00: 1,44$.

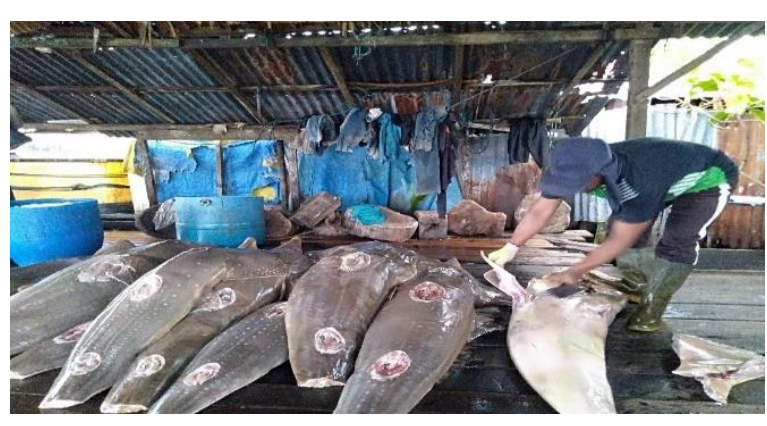

Gambar 3 Ikan pari kemejan yang didaratkan oleh nelayan di PPI Sungai Kakap

Pengamatan panjang dan berat tubuh dimaksudkan untuk mengetahui keadaan pertumbuhan ikan. Pada penelitian ini dilakukan analisis hubungan panjang dan bobot tubuh ikan pari kemejan pada 100 ekor sampel, yang terdiri dari 41 ekor ikan jantan dan 59 ekor ikan betina. Dari perhitungan regresi hubungan antara panjang dan baku ikan dengan berat tubuh ikan pari didapatkan nilai a sebesar 20,643 dan nilai b sebesar 0,6770 yang bersifat allometrik negatif. Hasil ini berbeda dengan hasil penelitian untuk spesies yang sama di perairan Sungai Menduk Kabupaten Bangka yang memiliki pola pertumbuhan allometrik positif untuk ikan jantan dan ikan betina (Suhendra $d k k$, 2017). Nilai b dapat bervariasi antar spesies dalam genus yang sama serta stok dari spesies yang sama. Nilai b berbeda tidak hanya antar spesies, tetapi juga ada antara stok spesies yang sama karena jenis kelamin, kematangan, musim, dan waktu karena perubahan dalam perut kekenyangan (Bagenal dan Tesch, 1978). 


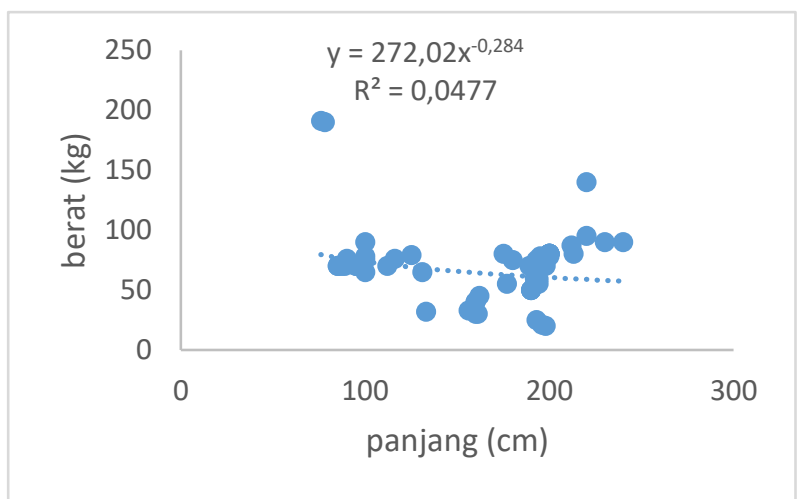

a

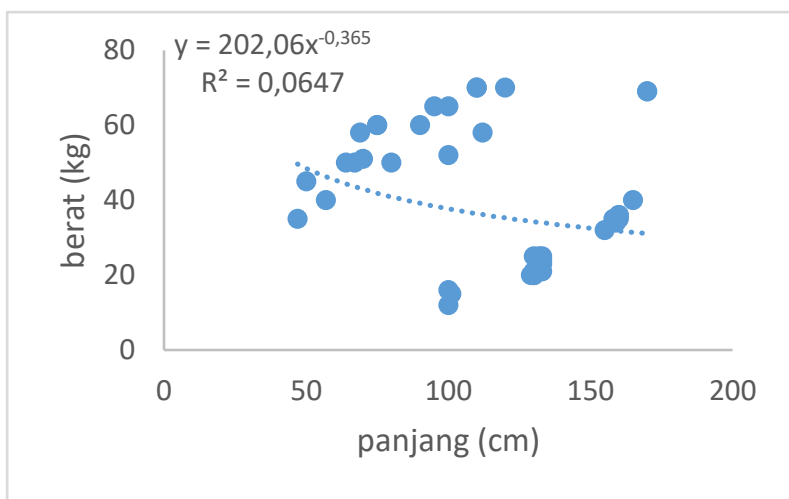

b

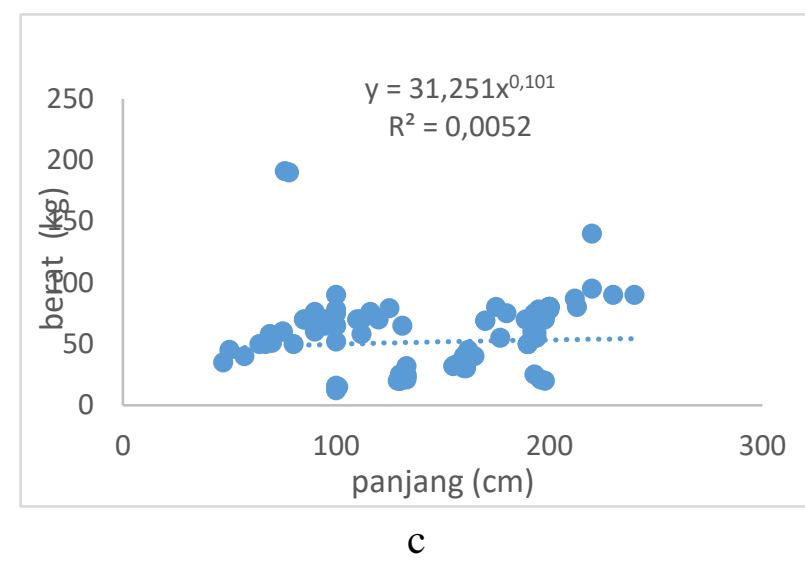

Gambar 4 Hubungan panjang dan berat baku pari kemejan betina (a), pari kemejan jantan (b), serta betina dan jantan (c)

Berdasarkan hasil analisis regresi linier sederhana antara panjang badan dan berat ikan pari kemejan, diperoleh $\mathrm{T}$ tabel $=$ 20,643 dan $\mathrm{T}$ hitung $=0,6770$. Dari hasil Thitung dan $\mathrm{T}$ tabel tersebut dapat diketahui pola pertumbuhan ikan pari kemejan bersifat allometrik negatif yaitu pertumbuhan panjang lebih cepat dari pada pertumbuhan berat, pertambahan panjang juga diimbangi dengan pertambahan berat. Tetapi pada ikan pari kemejan lebih cepat bertambah panjang dari pada pertambahan beratnya. Kondisi tersebut diperkirakan karena adanya faktor ekologis dan biologis, sebagaimana diungkapkan oleh Merta (1993).
Hubungan panjang dan berat tidak selalu bersifat tetap, nilainya juga dapat berubah dan berbeda antara satu lokasi dengan lokasi lainnya, hal ini dikarenakan ada faktor-faktor biologis, dan ekologis yang mempengaruhi habitat ikan pari sebagaimana telah dijelaskan di atas. Hal tersebut sesuai dengan pernyataan Sulistiono et al., (2001), dimana hubungan panjang dan berat menunjukkan pertumbuhan yang bersifat relatif artinya dapat berubah menurut waktu. Apabila terjadi perubahan terhadap ketersediaan makan dan lingkungan diperkirakan nilai ini juga akan berubah.

Berdasarkan Gambar 3, terlihat bahwa ikan pari kemejan jantan memiliki kisaran panjang tubuh 47-170 cm dan bobot 
tubuh $12-70 \mathrm{~kg}$, sedangkan kisaran panjang tubuh ikan pari kemejan betina 76-240 cm dan bobot tubuh 21-90 kg. Perbedaan kisaran panjang dan bobot tubuh tersebut disebabkan persaingan makanan yaitu jumlah ikan-ikan lain yang memanfaatkan makanan yang sama dan ketersediaan makanan di Perairan Selat Makasar, umur, jumlah antara individu jantan dan betina serta tingkat kematangan gonad (TKG). Menurut Effendie (1997), faktor

\section{KESIMPULAN}

Hubungan panjang dan bobot ikan pari kemejan jantan dan betina yang didaratkan di PPI Sungai Kakap menunjukkan pola pertumbuhan yang bersifat alometrik negatif, yaitu pertumbuhan panjang lebih cepat daripada pertumbuhan bobot tubuh.

\section{UCAPAN TERIMA KASIH}

Penulis mengucapkan terima kasih kepada Dekan Fakultas Pertanian dan Ketua Program Studi Manajemen Sumberdaya Perairan Universitas Tanjungpura atas dukungan terhadap penelitian ini. Kepada Kepala Balai Pengelolaan Sumberdaya Pesisir dan Laut Pontianak dan Kepala Stasiun Pengawasan Sumberdaya Kelautan dan Perikanan Pontianak yang telah mengizinkan penulis untuk melakukan penelitian dan memberikan data pendukung untuk kepentingan penelitian.

\section{DAFTAR PUSTAKA}

Bagenal T B, Tesch F W. 1978. Age and Growth. In: Methods for Assessment of fish Production in Freshwater. Bagenal T.B. (ed), pp.100-136, 3rd Edition, yang mempengaruhi pertumbuhan ikan adalah ukuran, umur, temperatur dan kualitas air, dan jenis ikan itu sendiri, serta jumlah ikan-ikan lain yang memanfaatkan sumber yang sama. Menurut pendapat lain yaitu Biring (2011) ukuran tubuh ikan pari jantan lebih kecil di bandingkan dengan ikan pari betina, factor yang mempengaruhi diantaranya adalah pertumbuhan ikan pari betina lebih cepat dari pada ikan pari jantan.

Rlacwen Scientific Publication, Oxford,uk.

Biring D. 2011. Hubungan Bobot Panjang Dan Faktor Kondisi Ikan Pari (Dasyatis kuhlii, Muller \& Henle, 1841) Yang Didaratkan Di Tempat Pelelangan Ikan Paotere. Makassar Sulawesi Selatan. Skripsi [Tidak dipublikasikan]. Program Studi Manajemen Sumberdaya Perairan, Jurusan Perikanan, Fakultas Ilmu Kelautan dan Perikanan Universitas Hasanudin, Makassar. Hal ; 18-25.

[BPSPL Pontianak] Balai Pengelolaan Sumberdaya Pesisir dan Laut Pontianak. 2018. Laporan Monitoring dan Pendataan Hiu dan Pari di Kalimantan Barat. BPSPL Pontianak, Pontianak.

Dharmadi, Sunarno M T D, Edrus I N. 2011. Perikanan dan Aspek Biologi Ikan Pari Lampengan, Mobula japanica di Perairan Selatan Jawa. BAWAL 2(6): 369-376.

Effendie, M I. 1997. Biologi Perikanan. Yayasan Pustaka Nusatama. Yogyakarta.

Harlyan. Andini K, Meysella A, Ranny R Y. 2015. Pendataan Hiu Yang Didaratkan Di Pelabuhan Perikanan Pantai Muncar, Banyuwangi. Jurusan Pemanfaatan Sumberdaya Perikanan dan Kelautan, Universitas Brawijaya: Malang. 
Jayadi M I. 2011. Aspek Biologi Reproduksi Ikan Pari (Dasyatis kuhlii Müller \& Henle, 1841) Yang Didaratkan di Tempat Pelelangan Ikan Paotere Makassar. Skripsi [Tidak dipublikasikan]. Program Studi Manajemen Sumberdaya Perairan, Jurusan Perikanan, Fakultas Ilmu Kelautan dan Perikanan Universitas Hasanudin, Makassar. Hal; 24-28.

Merta I G S. 1993. Hubungan Panjang Berat dan Faktor Kondisi Ikan Lemuru (Sardinella lemuru) Bleeker, 1953 dari Perairan Selat Bali. Jun. Pen. Per. Laut (73) : 35-44

Musick J A, Burgess G, Cailliet M, Camhi, Fordham S. 2000. Management of Sharks and Their Relatives (Elasmobranchii). Fisheries.March, 913.

Omar A, Bin S. 2009. Modul Praktikum Biologi Perikanan. Jurusan Perikanan,
Fakultas Ilmu Kelautan dan Perikanan, Universitas Hasanuddin, Makassar.

Sadidi D, Mustika C, Sarmintohadi .2014.Pedoman Identifikasi dan Pengenalan Pari Manta. Direktorat Konservasi Kawasan dan Jenis Ikan Jakarta.

Sari I W. 2007. Biologi Reproduksi Ikan Keperas (Cyclocheclicthys apogon) di Sungai Musi Sumatera Selatan. [skripsi]. Fakultas Perikanan dan Ilmu Kelautan Institut Pertanian Bogor.

Suhendra C, Eva U, Umroh. 2017. Biologi reproduksi ikan keperas (Cyclocheilichthys apogon) di Perairan Sungai Menduk Kabupaten Bangka.Jurnal Sumberdaya Perairan 11(1): 1978-1652.

Sulistiono M, Arwani, Aziz K A. 2001. Pertumbuhan Ikan Belanak (Mugil dussumierf) Di Perairan Ujung Pangkah, Jawa Timur. Jurnal lkhtiologi Indonesia. 1(2):39-47. 